\title{
Barriers to Entry and Returns to Capital in Informal Activities: Evidence from sub- Saharan Africa
}

\author{
Michael Grimm ${ }^{a}$, Jens Krüger ${ }^{b, c}$, Jann Lay ${ }^{b, c^{*}}$
}

May 2011, Forthcoming in The Review of Income and Wealth, 57:

S27-S53.

\begin{abstract}
This paper investigates the patterns of capital entry barriers and capital returns in informal micro and small enterprises (MSEs) using a unique micro data set seven West-African countries. Our findings support the view of a heterogeneous informal sector that is not primarily host to subsistence activities. While an assessment of initial investment identifies some informal activities with negligible entry barriers, a notable cost of entry is associated to most activities. We find very heterogeneous patterns of capital returns in informal MSEs. At very low levels of capital, marginal returns are extremely high - often exceeding 70 percent per month. Above a capital stock of 150 international dollars, marginal returns are found to be relatively low at around 4 to 7 percent monthly. We provide some evidence that the high returns at low capital stocks reflect high risks. At the same time, most MSEs appear to be severely capital constrained.
\end{abstract}

Keywords: Informal enterprises, entry barriers, returns to capital

JEL Classification: D22, D24, 012, 017

\footnotetext{
a International Institute of Social Studies, Erasmus University Rotterdam, The Hague, The Netherlands

${ }^{\mathrm{b}}$ University of Göttingen, Germany

c GIGA German Institute of Global and Area Studies, Hamburg, Germany

* Corresponding author: Jann Lay, University of Goettingen and GIGA German Institute of Global and Area Studies, Institute of Latin American Studies (ILAS), Neuer Jungfernstieg 21 / 20354 Hamburg / Germany, Tel. ++49-(0)40-42825-763, E-Mail: lay@giga-hamburg.de
} 


\section{Acknowledgements}

Comments by Francisco Ferreira, two anonymous referees and the participants of the IARIW Special Conference on Measuring the Informal Economy in Developing Countries, Kathmandu, in particular by Panos Tsakloglou, have been very helpful. The paper also benefitted from comments received at the CSAE conference 2011 in Oxford and the development economics workshop 2011 at Tilburg University.

This research is part of a project entitled "Unlocking potential: Tackling economic, institutional and social constraints of informal entrepreneurship in Sub-Saharan Africa" (http://www.iss.nl/informality) funded by the Austrian, German, Norwegian, Korean and Swiss Government through the World Bank's Multi Donor Trust Fund Project: "Labor Markets, Job Creation, and Economic Growth, Scaling up Research, Capacity Building, and Action on the Ground". The financial support is gratefully acknowledged. The project is led by the International Institute of Social Studies of Erasmus University Rotterdam, The Hague, The Netherlands. The other members of the research consortium are: AFRISTAT, Bamako, Mali, DIAL-IRD, Paris, France, the German Institute of Global and Area Studies, Hamburg, Germany and the Kiel Institute for the World Economy, Kiel, Germany.

\section{Disclaimer}

This is work in progress. Its dissemination should encourage the exchange of ideas about issues related to entrepreneurship and informality. The findings, interpretations and conclusions expressed in this paper are entirely those of the authors. They do not necessarily represent the views of the World Bank, the donors supporting the Trust Fund or those of the institutions that are part of the research consortium.
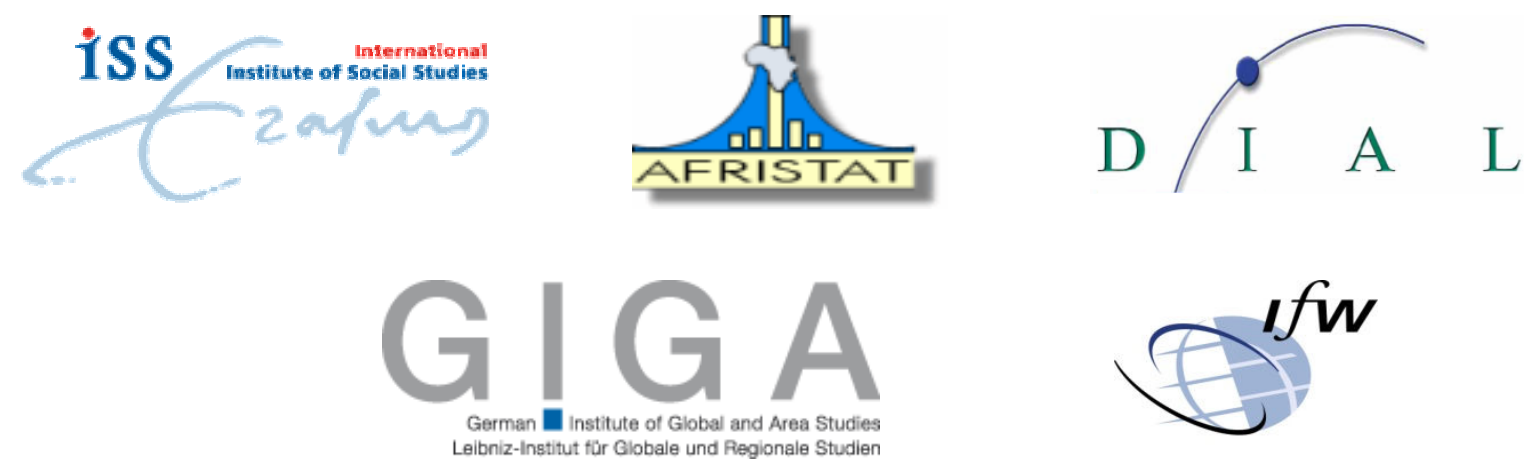


\section{Table of Content}

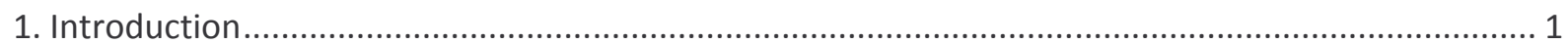

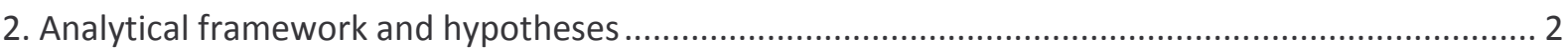

3. Entry costs and capital returns in African MSEs ............................................................................ 4

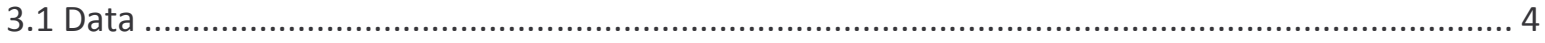

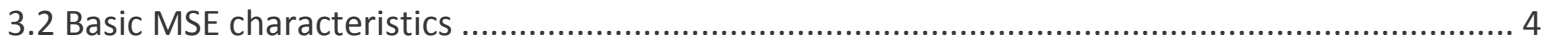

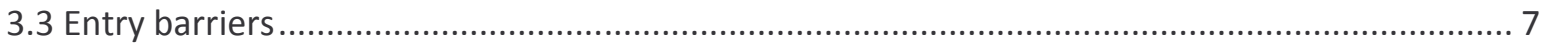

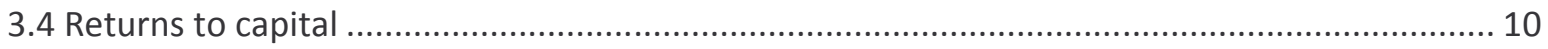

3.5 Returns to capital with a household fixed-effect ..................................................................... 14

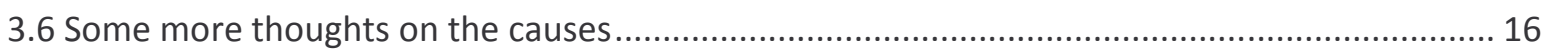

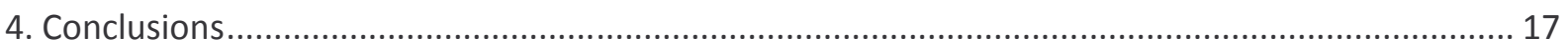

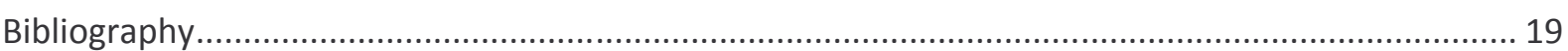




\section{Introduction}

Most urban dwellers in the poor developing world make their living from informal micro and small enterprises (MSEs) and the performance of those enterprises often decides upon livelihood success and failure. Successful entrepreneurs seem to co-exist with the masses of petty traders or other menial workers who hardly can make a living from what they earn. It is widely assumed that the earnings potential of many of those entrepreneurs is not exploited, as they face important economic constraints, for example entry barriers and limited access to credit thus providing a rationale for policy interventions, such as microcredit programs. The presence of entry barriers combined with capital market imperfections may indeed explain the heterogeneity amongst informal entrepreneurs in developing countries. In poverty trap models, ${ }^{1}$ returns to capital below a certain threshold of investment are often assumed to be very low or even zero, as entry of other poor individuals into this subsistence segment of the informal sector eats up potential returns. Only if entrepreneurs are wealthy enough or can obtain credit to overcome the barrier to entry, they can earn much higher returns. Returns to capital in MSEs can thus be regarded as a key indicator of the unexploited potential of informal entrepreneurship.

Despite an abundant literature on the informal sector in developing countries (Moser, 1978, Peattie, 1987, Rakowsky, 1994, Maloney, 2004, Henley et al., 2006), the empirical literature on entry barriers and returns to capital in MSEs is fairly recent and surprisingly little extensive. This is all the more remarkable since a very early insight from the literature on the informal sector is that it comprises very heterogeneous activities or, more specifically, heterogeneous forms of production (Hart, 1973). Existing studies on capital returns consistently find very high - not low - returns, often in the order of more than 60 percent annually (e.g. Banerjee and Duflo, 2004, de Mel et al., 2008). De Mel et al. (2008), for instance, use data from a randomised experiment to estimate returns to capital of Sri Lankan microenterprises. In this experiment, the authors randomly give cash or in-kind transfers, which represent 55 to 110 percent of the median investment, to microenterprises. They find a significant and positive correlation between transfers and real profits of the enterprises. Using the random treatment as an instrument for changes in the capital stock the authors estimate the returns to capital to be in a range from 55 to 70 percent per year. McKenzie and Woodruff (2006) find very high returns at low levels of capital, yet little evidence for the existence of high entry costs, for the case of informal Mexican enterprises, although start-up costs vary considerably by sector. As we will follow their empirical approaches very closely, our findings can be readily compared to theirs. For Sub-Saharan Africa (SSA), there is also evidence of extremely high returns to capital (Udry and Anagol, 2006, Schündeln, 2004, Kremer, Lee and Robinson, 2010). Kremer et al. (2010) for instance study retail firms in rural Kenya and find an average annual real marginal rate of return of 113 percent although with ample heterogeneity across firms. The rates of returns are derived from information on

\footnotetext{
${ }^{1}$ See, for example, Banerjee and Newman (1993), Aghion and Bolton (1997) or Lloyd-Ellis and Bernard (2000).
} 
foregone earnings due to insufficient inventory or stock-outs, and alternatively, by assessing whether firms take advantage of quantity discounts from wholesalers. Both procedures yield very similar estimates.

With respect to the causes of the observed pattern of high returns at relatively low levels of capital, the evidence is inconclusive, although some findings do suggest an important role for capital market constraints (Banerjee and Duflo, 2004, Schündeln, 2006, de Mel et al., 2008). In general, high returns in MSEs point at the huge potential of this type of activities, as a very large share of urban employment is generated by MSEs: Based on the same dataset used in this paper, Brilleau, Roubaud and Torelli (2005) find for instance the share of informal sector employment ${ }^{2}$ to uniformly exceed 70 percent in urban West-Africa.

In this paper we estimate capital returns for West-African MSEs and examine entry barriers into small-scale economic activities. More specifically, we address the following questions in the context of Sub-Saharan Africa: First, do informal activities exhibit high entry barriers (start-up costs) relative to the income and wealth levels of entrepreneurs? Second, how do capital returns vary with the size of the capital stock; do we also find high returns at low levels of capital or the inverse as some of the theoretical literature suggests? And third, what can be said about the causes of the observed patterns of capital returns? To answer these questions, we use a unique, albeit cross-sectional, micro data set on informal enterprises covering the economic capitals of seven West-African countries. In our empirical approaches, we very closely follow the study by McKenzie and Woodruff (2006).

The remainder of the paper is organised as follows. Section 2 outlines our analytical framework and formulates the hypotheses that are tested in Section 3. Section 4 concludes.

\section{Analytical framework and hypotheses}

In what follows we develop a simple model in which prospective entrepreneurs face entry barriers and non-convex production technologies and then derive testable assumptions under alternative hypotheses about capital market imperfections. In the literature on entrepreneurial activity in developing countries, incomplete capital markets have long been stressed as a major economic constraint (e.g. Tybout, 1983, Bigsten et al., 2003). If capital markets function poorly because credit contracts cannot be easily enforced, so goes the argument, capital fails to flow to its most productive uses and marginal returns across entrepreneurial activities are not equalised. Faced with different costs of capital because of differences in wealth and their capacity to provide collateral, borrowers may have to choose to invest in different technologies (Banerjee and Duflo, 2005).

In such a setting, the informal sector may be divided into different segments characterised by different entry barriers in terms of skill or capital requirements (e.g. Fields, 1990, Cunningham and Maloney, 2001). This basic idea is reflected and formalised in a number of models of economic development and poverty traps, which emphasize the role of the

\footnotetext{
${ }^{2}$ In Brilleau, Roubaud and Torelli (2005) and in this paper, informal sector employment is understood to comprise employment in firms that neither have formal written accounts nor are registered with the tax administration. Employment or self-employment in those enterprises can be considered informal by almost any definition of informality one may want to apply.
} 
distribution of wealth (e.g. Banerjee and Newman, 1993, Galor and Zeira, 1993). In these models, the segmentation of economic activities and the co-existence of high and low returns are caused by the interaction of non-convex production technologies and capital market imperfections. If gainful entrepreneurial activities require a certain level of start-up capital that cannot be obtained from capital markets, poorly endowed individuals will be prevented from entry. This implies that poor individuals get stuck in low-productivity activities and hence the whole economy may end up in a poverty trap; the higher the share of initially poor people, the higher the share of those in low-productivity industries. ${ }^{3}$

Hence, these models typically assume very low levels of returns, or subsistence returns, at very low levels of capital and higher returns once a certain threshold has been passed. In the simplest of worlds, the entrepreneur maximises the difference between output $y$ and the costs of capital ( $r k$ ), i.e. profit $\pi$ subject to his borrowing constraint $\bar{B}$. He can only produce a non-zero output using neoclassical technology $f$ if he is able to raise at least $\bar{K}$. Otherwise his production will be eaten entirely by the costs of capital and his profit will be zero.

Max.

$$
\pi=y-r K
$$

s.t.

$$
\begin{array}{lll}
y=f(K) & \text { if } & K>\bar{K} \\
y=r K & \text { if } & K \leq \bar{K} \\
K \leq \bar{B} & &
\end{array}
$$

The entrepreneur will chose his capital stock such that

$$
f^{\prime}(K)=r \quad \text { if } \quad \bar{B}>\bar{K}
$$

If his borrowing constraint is binding, i.e. $\bar{B} \leq \bar{K}$, then the entrepreneur will be indifferent between different sizes of capital stock, as he earns zero profits anywhere between $0 \leq K \leq \bar{K}$. Returns to an additional unit of capital, i.e. $\pi^{\prime}(K)$, will hence be 0 between $0 \leq K \leq \bar{K}$. Once his borrowing capacity allows the entrepreneur to pass the threshold $\bar{K}$, he earns very high marginal returns that fall to zero when he reaches the optimal level of capital $K^{*}$. The resulting patterns of marginal returns to capital as a function of the borrowing constraint $B$ are presented in the graph below.

\footnotetext{
${ }^{3}$ Risk and risk aversion can also create such poverty traps.
} 
Place Figure 1 here.

This small exposition allows us to formulate two basic hypotheses to be tested subsequently:

First, the existence of a threshold $\bar{K}$ should be observable in the distribution of initial investment undertaken by MSEs. Second, returns to capital should be low at low levels of capital, and high but decreasing in $K$ at higher levels. Note that this theoretical insight contradicts most of the empirical evidence presented in the introduction. In what follows, we will test whether this framework has also to be rejected for the economies we focus on.

\section{Entry costs and capital returns in African MSEs}

\subsection{Data}

We test these hypotheses by using data from a set of surveys (1-2-3 surveys or Enquêtes 1-23 ) in seven economic capitals of the West-African Economic and Monetary Union (WAEMU) in the early 2000s. ${ }^{4}$ A 1-2-3 survey is a multi-layer survey organised in three phases and specially designed to study the informal sector. ${ }^{5}$ Phase 1 is a representative labour force survey collecting detailed information on individual socio-demographic characteristics and employment. Phase 2 is a survey which interviews a representative sub-sample of informal production units identified in Phase 1 . The focus of the second phase is on the characteristics of the entrepreneurs and their production unit, including the characteristics of employed workers. It also contains detailed information on input use, investment, sales and profits. Phase 3 is a household expenditure survey interviewing (again) a representative sub-sample of Phase 1. The data of all three phases is organised in a way so that it can be linked. For this paper we use data from Phase 2 which hence is a sub-sample of informal entrepreneurs in seven West-African urban centres (Brilleau, Ouedraogo, and Roubaud, 2005).

\subsection{Basic MSE characteristics}

The 1-2-3 surveys define informal enterprises as production units that (a) do not have written formal accounts and/or (b) are not registered with the tax administration. Part (b) of this definition varies slightly between countries, as registration may not always refer to registration with tax authorities. The so-defined informal sector accounts for the vast majority of employment in the WAEMU cities covered by the surveys, as illustrated in Table 1. The share of informal sector employment exceeds 70 percent in all cities considered - in Cotonou and Lomé even 80 percent. Employment in informal firms is typically selfemployment, i.e. the employed individual is also the MSE owner, but employed and/or

\footnotetext{
${ }^{4}$ These urban centres are Abidjan, Bamako, Cotonou, Dakar, Niamey, Lomé and Ouagadougou. The surveys have been carried out by AFRISTAT and the National Statistical Institutes (INS) with the support of DIAL as part of the Regional Program of Statistical Support for Multilateral Surveillance (PARSTAT) between 2001 and 2003. For a more detailed description of the data see Brilleau, Ouedraogo and Roubaud (2005).

${ }^{5}$ See Roubaud (2008) for a detailed assessment of this type of survey instrument.
} 
helping family- and non-family workers account for 30 to 40 percent of employment in this sector.

Place Table 1 here

The 1-2-3 surveys do not (explicitly) apply a size criterion, but more than 90 percent of the enterprises employ a maximum of three people including the owner and possibly employed family members. As shown in Table 1, around 70 percent of informal enterprises function in 'pure self-employment' mode, i.e. they only consist of the owner her- or himself. Accordingly, the average enterprise size - including all employed family- and non-familymembers - is only 1.6 individuals. The information in Table 2 has been computed from a sample of 6,521 informal enterprises from all seven countries that will be used for all the subsequent empirical analyses. This number includes 243 MSEs reporting zero profits and 892 MSEs reporting zero capital stock.

Albeit small, these enterprises had been in operation since more than seven years on average. The median age, however, is significantly lower with only five years. Owner's experience in the business is typically lower than the enterprise age, mainly reflecting that some MSEs are transferred within the family. MSE owners have only 3.7 years of schooling on average and about half of them are female.

Average monthly profits of informal enterprises are about 380 International Dollar (Int. \$) with median profits at $112 \mathrm{Int}$. \$. Profits are computed as value added (sales minus input costs including expenses for products for re-sale) minus expenses for hired labour. The questionnaire has very detailed sections on sales of transformed, non-transformed/re-sold products as well as offered services. The same holds for the input side that covers raw materials, intermediates, products for re-sale, taxes, rents and other utility costs. All these items are covered for the last month in the survey. Note that interest payments must not be deducted from value added.

Average capital stock is fairly high with about 1000 Int. \$, but this result is driven by a few MSEs with very high capital stocks - the median MSE capital endowment stands at only 75 Int. \$. We measure capital stock by the replacement value of all business-related assets, including the business establishment, machines, furniture, vehicles and utilities. More specifically, the entrepreneur is asked to report all the equipment that he has used in the last year to operate his business and the replacement value of each item. ${ }^{6}$ While this implies that the corresponding equipment is used for the operation of the business, it is impossible to determine whether this is its sole use or whether it is also used for other purposes in the household. We will come back to this point in the discussion of our results. Another complication of computing capital stocks stems from the fact that capital is also bound by inventories (or stocks of raw materials). This is ignored in the above calculation, but we will take this into account when we analyse entry barriers and returns to capital below.

\footnotetext{
${ }^{6}$ Unfortunately, we do not have any information about sales of or damage to capital goods
} 
Place Table 2 here.

For a first assessment of MSE heterogeneity, we also report the above characteristics by capital quintiles. The first quintile basically works without capital and these MSEs mainly comprise trading activities and other services (industry composition not reported). The profits of these enterprises are around 200 Int. \$, almost two times median profits. Typically, these MSEs are self-employed individuals. This also holds for entrepreneurs in the second capital quintile. They resemble those without capital, but are significantly less educated and earn about 30 Int. \$ less per month. In the third quintile, profits are more than 70 percent higher than in the second quintile while the average capital stock approximately quadruples. Yet, it remains low at only about 80 Int. \$ on average. The MSEs have owners who still have below average years of schooling, but 0.7 years more than those with very little capital. Fewer owners are female and their firms are slightly bigger than in the lower quintiles. From the third to the fourth quintile, changes are similar to moving from the second to the third. Capital stock again quadruples, owner's average education increases, as does firm size and the share of male owners. However, monthly profits only increase by $70 \mathrm{Int}$. \$ on average to 370 Int. \$. Much more pronounced are the differences in capital and profits between the fourth and the fifth quintile. Average capital stock of MSEs in the fifth quintile is almost 5 000 Int. \$ and monthly profits are much higher than in other enterprises. These entrepreneurs also tend to be much better educated than the average and more than half of them employs at least a second person.

These descriptive statistics indeed hint at a considerable degree of heterogeneity within the informal sector although MSEs of the bottom 40 percent of the capital distribution share a number of common characteristics. This heterogeneity - also in profits - seems to be linked to capital stock, which, in turn, may be associated to the respective sector of activity. Therefore, Table 3 shows the industry distribution of the MSEs for each country and for the sample as a whole. Overall the most important sector is 'petty trading' (27.1 percent), followed by 'other manufacturing and food' (16.1 percent) and 'other services' (11.8 percent), i.e. services that are not covered by the other listed industries. The smallest sector in terms of its share is the transport sector, which is likely to require substantial start-up costs, including investment in physical capital and cost for licences (4.6 percent). The relative importance of the various industries is in line of what one would expect when looking at demand patterns. Whereas small services, small traded goods and food have a high share in the households' budgets, transport or repair services have a rather small share. It is also interesting to see that the industry distribution is relatively homogenous across the seven countries, with two exceptions though: 'Other manufacturing and food' are particularly frequent in Ouagadougou and Niamey. These cities have in turn relatively low shares for the sector 'hotels and restaurants', so it might be that the border between 'producing or processing food' and 'selling food in a restaurant' was not drawn exactly in the same way in the seven cities under study. The industry composition seems to be relatively unrelated to 
the level of GDP per capita; the richer centres in the sample such as Abidjan and Dakar have not a substantially different distribution than Niamey and Lomé.

Place Table 3 here.

\subsection{Entry barriers}

We now turn to the empirical analysis of the existence of entry barriers into informal activities. We expect that MSEs engage in petty (or subsistence) activities that require little capital as well as more capital intensive activities that involve considerable initial investment. In some industries we expect more of these activities, for example in trade, than in others, for example in transport. We therefore first analyse distributions of initial investment in equipment that should reflect these patterns. In a second step, we also consider other start-up costs including expenses for other inputs and inventories.

Before we quantitatively examine these entry barriers, we briefly report and comment some evidence from questions that ask entrepreneurs for the problems they face. Table 4 reports the share of entrepreneurs who report to have problems in a specific area. We distinguish MSEs (only in the clothing and apparel sector to reduce heterogeneity) by their age in order to determine whether those problems are different when an enterprise starts operating. Two groups of problems figure prominently for MSEs in the clothing and apparel sector; on the one hand, those related to the lack of demand (not enough clients, too much competition) and, on the other, those associated to the access to capital in broad sense (access to credit, lack of locality, machines, and equipment). Access to raw material is a problem only for 25 percent of the MSEs, but much more so for younger ones. Demandrelated problems seem to be equally important for MSEs at all ages, and so for a vast majority. Half of the firms report to have inadequate access to credit. The answer to this question (and the next question on credit too expensive) is likely to be biased by actual experience of demanding/being declined credit, which might explain why more of the older firms report to have problems in this area. This seems plausible, as problems that result from credit constraints, such as the lack of locality, machines, and equipment, are indeed cited more frequently by younger firms suggesting that these costs may represent important barriers to entry. Other constraints, such as the lack of qualified personnel, technical or management problems, and institutional or governance constraints appear to be much less important. There is also no evidence that these problems are more important when firms start operating. ${ }^{7}$

Place Table 4 here.

\footnotetext{
${ }^{7}$ We are aware that these descriptive statistics are biased by the fact that some constrained firms never set up a shop. This also holds for the subsequent analyses and is a bias that is impossible to address with the data at hand.
} 
Although our dataset is cross-sectional, it allows us to identify investment paths since, for each enterprise asset, we know the date of purchase. Furthermore, we know when an enterprise has been established. As a proxy for initial investment in equipment we therefore use the accumulated investment undertaken during the first year of operation. As we expect measurement error in the investment history of MSEs in our data to be severe for investments undertaken a long time ago, the subsequent analysis of this section only considers enterprises that have been established four years before the survey or later. This leaves us with a sub-sample of 3144 informal enterprises.

We first examine initial investment by industry. Table 5 hence shows the replacement value of business assets accumulated in the first year of operation at certain quantiles of the initial-investment distribution. The statistics are again based on the pooled data from all seven countries in the dataset.

Place Table 5 here.

Overall, levels of initial investment in equipment are fairly low. Quite a number of activities do not seem to require any initial investment. This holds for 31 percent of all enterprises and somewhat less for "capital intensive" informal industries, such as repair services and hotels and restaurants. In most activities, initial investment however remains low also at higher quantiles. The median petty trader, for example, still does not invest more than 10 Int. \$ during the first year after establishing the enterprise. However, although 29 percent of all enterprises in the transport sector do report zero initial investment, the median initial investment of investing MSEs is about five times larger than for the repair services sector and the clothing sector, the industries with the second and third largest values. The top 25 percent in the transport sector invest more than 3400 Int. \$ in the first two years. Overall, there is substantial heterogeneity of initial investment across industries, ${ }^{8}$ as also illustrated by Figure 2 showing the distribution of (log) initial investment for all enterprises, the service, the manufacturing and the transport industries. Discontinuities in these distributions could be taken as a sign of entry barriers within a given sector. The service sector seems to have such a barrier at very low levels of capital of around 50 Int. \$. There are only some small spikes in the distribution for the manufacturing sector shows several discontinuities. The transport sector shows a more pronounced spike between 7 and 8 in log initial investment, i.e. above 1000 Int. \$. Overall, this brief descriptive analysis does not lend support to significant entry barriers that would be related to investment into equipment.

\footnotetext{
${ }^{8}$ It turns out that the distributions of start-up costs across industries in the different countries are fairly similar to those reported in Table 6.
} 
Place Figure 2 here.

However, as indicated above, entrepreneurs incur additional costs when they want to start a business. These costs include recurrent expenses, such as expenses for raw materials and building up inventories. While these costs will in principle be recovered once the final product is sold, they need to be financed when the business starts operating. Unfortunately, our dataset does not allow us to compute those costs at start-up. We only know the monthly recurrent expenses that we report in Table 6 (based on the same sample as Table 5) along with initial investment and median profits as a reference point. Admittedly, these monthly expenses are an imperfect proxy of this component of start-up costs. For some industries, for example the wholesale and retail sector, inventories bought during the last month may be a reasonable proxy for this component of start-up costs. A petty trading activity, however, can possibly be started with a fraction of the reported monthly purchases of inventories. Moreover, in many cases inputs may only be bought once an order has been received and hence these costs may have more the character of variable than fixed costs. The interpretation of these figures will hence be somewhat speculative. To illustrate the relative size of the different components of start-up costs, Table 7 also reports median monthly MSE profits.

Place Table 6 here.

While labour expenses seem to be negligible, monthly non-labour expenses can be substantial compared to initial investment. The industry patterns correspond to expectations with raw materials being more important for manufacturing and construction, while inventories account for the major part of non-labour expenses for trading activities. It seems that investment in equipment indeed accounts for a large part of start-up costs in manufacturing activities (with the likely exception of food processing). This is less the case at lower levels of capital, as the difference between mean and median is much smaller for nonlabour expenses than for initial capital. For trading activities, the costs of building-up inventories may be as important as initial investment in equipment.

A comparison of start-up costs with median monthly profits shows that both equipment costs and non-labour expenses can be substantial - albeit not insurmountable - in some industries while they are negligible in others. In the transport and the clothing and apparel sector, for instance, almost three months of earnings are necessary to cover median initial investment. When we combine the information on expenses on equipment capital and recurrent monthly costs, this adds up to less than 30 Int. \$ combined start-up costs for only 12 percent of the MSEs. Hence, while there are indeed some informal activities with negligible entry barriers, there is some fixed cost associated to entry into most informal activities. However, it should be noted that the costs shown here must be seen as an estimated upper bound. 


\subsection{Returns to capital}

We now turn to the estimation of the returns to capital at different levels of capital stock. Unfortunately, the cross-sectional character of our data does not allow us to estimate the returns to initial investment (or to additional investment), but only to total capital stock. In our empirical model, profits $\pi_{i h j}$ of MSE $i$ in household $h$ residing in country $j$ are not only a function of capital $K_{i h j}$, but also of a vector of exogenous variables $X_{i h j}$ and two unobserved factors, one at the household level $\vartheta_{h j}$, for example household wealth, and one at the individual level $\vartheta_{i h j}$, which we primarily think of as entrepreneurial ability. These factors do not only influence profit directly, but simultaneously determine the size of the capital stock.

$$
\pi_{i h j}=f\left(K_{i h j}\left(\vartheta_{h j}, \vartheta_{i h j}\right), X_{i h j}, \vartheta_{h j}, \vartheta_{i h j}\right)
$$

In log-linearised form and with $u_{i h j}$, a random error, the equation can be expressed as

$$
\ln \left(\pi_{i h j}\right)=\alpha+\beta_{K} \ln K_{i h j}+X_{i h j}^{\prime} \delta+\beta_{91} \vartheta_{h j}+\beta_{\vartheta_{2}} \vartheta_{i h j}+u_{i h j} .
$$

The observable exogenous characteristics of the entrepreneur in the models estimated below are the MSE owner's years of schooling, experience and gender. We also include total labour input in hours (including both household and hired labour). Further 'exogenous' variables include industry and country dummies as well as industry-country interaction terms. As returns to capital, labour and schooling may differ across countries and industries we also include the corresponding interaction terms.

The cross-sectional estimation of equation (7) is confronted with a number of potential biases. First, $\beta_{K}$ may be biased due to the mentioned omitted variables that are correlated with both capital stock and profit. The classical example for such a variable is unobserved ability of an entrepreneur. Certain managers will have abilities that allow them to accumulate more capital and to generate more profits than others. The omission of these abilities will lead to an upward bias of $\beta_{K}$. Moreover, the estimation of equation (7) may be complicated by reverse causality. Higher profits allow faster capital accumulation, which would again lead to an upward bias of $\beta_{K}$. Finally, the estimation has to deal with classical measurement error in both profits and capital stocks, which will downward bias $\beta_{K}$. We explain below how we address these different biases.

A test for heterogeneity in returns, i.e. in $\beta_{K}$ as a function of $K$, can be introduced in various ways. Our approach is to simply split the sample into entrepreneurs with different levels of capital stock. Without the intention to ignore the above caveats, Table 7 below reports the results from OLS regressions for all enterprises and for sub-samples of low (lower than 150 Int. \$), medium (higher than 150 Int. \$ and lower than 1000 Int. \$) and higher capital stock (higher than 1000 Int. \$). These thresholds were chosen rather ad-hoc on the basis of the above shown distribution of initial investment (specifically the $1000 \mathrm{Int}$. \$ threshold) as well as non-parametric plots of capital profitability (profit/capital) against capital (not reported). The latter suggest very high capital profitability at low levels of capital that falls very quickly with increasing levels of capital. At around 150 Int. \$ capital profitability starts to decrease much slower than at lower levels. In addition, the thresholds were chosen such that the sub- 
samples remain sufficiently large. Applying these thresholds implies a split of the sample into about 50 percent of low-capital, 30 percent of medium-capital and 20 percent of high-capital MSEs.

We estimate equation (7) on these different samples as double-log-specification, i.e. we regress log profits on log capital and log labour using OLS. ${ }^{9}$ Note that the double-log specification assumes a constant capital elasticity of profits and marginal returns of capital our main variable of interest - eventually depend on capital profitability $(\pi / K)$. More precisely marginal returns will be the product of $\beta_{K}$ and $(\pi / K)$. Since the estimated elasticity is an average effect, we should compute (average) marginal returns at the average of $(\pi / K)$. However, we will also evaluate returns at different levels of capital stock that we know to exhibit different levels of capital profitability. In the first set of results reported in Table 7 below, we interact log capital with country dummies - with Dakar (Senegal) as the reference category. The second set of regressions, reported in Table 8, includes interactions of capital with industry dummies. Here, manufacturing has been chosen as reference category. ${ }^{10}$

Place Table 7 here.

The first column of Table 7 reports the results from the full sample. Overall, the estimations explain an acceptable portion of the variation in profits with R-squared always in the range between 0.3 and 0.4 . The coefficients of the control variables (not reported, but available from the authors on request $)^{11}$ correspond to expectations, but show quite some variation across countries. The profit elasticity of capital fluctuates between 0.18 and 0.25 between countries and formal tests reject parameter equality across countries. Evaluated at countryspecific mean capital-profitabilities these parameters translate into marginal returns to capital (MRK) between 3 and 13 percent per month. We now split the sample according to the thresholds defined above; the result for the three sub-sample are reported in columns two to four of Table $7 .{ }^{12}$ Column two of Table 7 shows one of the key results of this paper: Very high marginal returns at low levels of capital. With the exception of Togo (Lomé), monthly marginal returns to capital exceed 70 percent and are even much higher from some countries. This result is driven by very high profit-capital ratios at low levels of capital. Table

\footnotetext{
9 We also estimate a specification without taking logs regressing monthly profits on a second-degree polynomial in both capital and labour. The estimates are similar to those from the double-log specification and are available from the authors on request.

${ }^{10}$ The regressions exclude enterprises that report to operate without any capital (and/or zero profits), which leaves us with 5403 observations (of 6 584). We will address to the possible biases introduced by this procedure later. In all regressions, we drop influential outliers from our sample (and sub-samples) that we identify by the DFITS-statistic. As suggested by Belsley, Kuh, and Welsch (1980), we use a cutoff-value $\mid$ DFITS $\left.\right|_{i h j}>2 \sqrt{k / N}$ with, $k$ the degrees of freedom (plus 1 ) and $N$, the number of observations. This procedure reduces the (sub-) samples quite considerably; the losses in sample size range from 5 to 10 percent. This may partly be due to measurement and reporting errors, but it may also reflect the high degree of heterogeneity of informal MSEs.

${ }^{11}$ In the remainder of the paper we will discuss a number of findings that could not reported in a table due to space limitations. All these tables are available from the authors on request.

${ }^{12}$ All the results are robust to slight variations in the thresholds.
} 
7 shows that $\beta_{K}$ is significantly different from 0.29 (the base coefficient for Dakar) only for Niamey at the 10 percent level, which is why an F-test for the joint significance of the capital-country interactions does not reject parameter equality across countries for MSEs with low capital stocks.

At higher levels of capital, the marginal returns to capital are much lower. This is despite the fact that the coefficient of log capital increases with higher capital stocks. Profit-capital ratios are, however, much lower at higher levels of capital stock. At medium levels of capital between 150 and $1000 \mathrm{Int}$. \$, the log capital coefficients differ significantly and considerably between countries. For Abijan, Bamako, and Niamey, the interaction terms are strongly negative and hence the correlation between log profits and log capital is not significantly different from zero for this set of countries in this range of capital stock. The implied MRKs are even negative in those cases. For the other countries, we find MRKs around 13 to 14 percent with the exception of Senegal where monthly returns amount to 38 percent. At levels of capital above 1000 Int. $\$$, there seems to be less heterogeneity. Only for Cotonou and Niamey are capital coefficients much lower than in Dakar. This also explains why the MRKs are much lower for these countries. The low returns for Lomé, in contrast are driven by a low profit-capital ratio. In the other countries, monthly capital returns are between 7 and 13 percent.

It is difficult to identify patterns in these results that could, for example, be explained by the level of development. Yet, they may be partly driven by differences in the industry composition of informal MSEs across countries (see Table 3 above). As our dataset is not large enough to include to full set of country-industry-capital interaction terms, ${ }^{13}$ Table 8 therefore reports the results from regressions that instead of country-capital interactions include industry-capital interactions. We have aggregated industries into four categories: (1) Manufacturing, (2) construction, hotels, transport, (3) trade, and (4) repair and other services. $^{14}$

Place Table 8 here.

The results suggest that the cross-country heterogeneity identified above may indeed be partly explained by differences in industry compositions. Overall, we find much less heterogeneity in the capital coefficient across industries than across countries. In fact, at medium and high levels of capital none of the industry-capital interaction terms turns out to be significant (columns three and four of Table 8). Marginal returns at these levels of capital are 4 percent for the repair and other services sector, and 6 or 7 percent for all other sectors. In this specification, there is now more heterogeneity in returns at low levels of capital. However, even though MRKs fluctuate between 47 percent (for repair and other

\footnotetext{
${ }^{13}$ Alternatively, one may analyze the variation within one industry and include country-capital interactions. The only industry with a sufficient number of observations for such an exercise is the trade sector. The results (not reported) confirm our main finding. Marginal returns to capital at low levels of capital stock exceed $65 \%$ except in Lomé and Bamako (35 and 33 \% respectively).

${ }^{14}$ Within these aggregate sectors, capital coefficients were found to be homogeneous.
} 
services) and 268 percent (for construction, hotels, and transport), the main finding from above is not altered: We consistently find very high marginal returns to capital at low levels of capital. ${ }^{15}$ In the following, we discuss the robustness of the above results and present number of additional robustness and specification checks. We first address the possible implications of how we measure our key variables and the problem of missing or zero values for capital and profits. Then, we analyse parameter heterogeneity by gender. Finally, we address the possibility of omitted variable biases, in particular ability bias.

Measurement error of both profits and capital tend to bias the estimated coefficients towards zero, so this source of bias does not give rise to major concerns in light of the significant strong effects. It is difficult to judge whether and how measurement error changes with higher or lower levels of profits and capital stock. We think there is little reason to assume that measurement error is less pronounced at lower levels of capital stocks, which would then partly explain higher returns at lower levels of capital. For capital, we have briefly discussed the problem that capital might not just be used for business purposes. How this affects our estimates depends on whether non-business use is systematically higher or lower at higher levels of capital. One may argue that more expensive capital goods, like machines, are likely to be of exclusive use to the business. Yet, our estimates of similar capital returns across industries can be taken as evidence against systematic differences in non-business use of reported capital stock. ${ }^{16}$

The inclusion of zero and missing values (as zeros) for the capital stock into the regressions lowers the estimated returns to capital, but the estimated coefficients still indicate very high but decreasing returns at low levels of capital. In turn, the coefficients on labour, education, and experience are much higher. The size of the sub-sample, which again is reduced by excluding influential outliers, increases by almost 1000 observations. We have also run Tobit regressions that explicitly model censoring without however major implications for the results.

Heterogeneity in returns may also stem from gender differences, as shown for example by de Mel et al. (2008) for Sri Lankan MSEs. To test this hypothesis we also run regressions (on the entire and the split samples) that include - instead of country-capital or industry-capital interactions - interactions of key inputs with the female-owner dummy. ${ }^{17}$ For all inputs, including capital, the coefficients are only found to be significantly different for females at higher levels of capital stock. This also holds for capital profitability that is much higher for males than for females at higher levels of capital stock. This implies that marginal returns to capital are very high for both males and females at low levels of capital stock (albeit a bit lower for females). In both the medium and the high capital stock range, female marginal returns are much lower with about 2 percent compared to 8 and 7 percent for males.

\footnotetext{
${ }^{15}$ Semi-parametric estimates (not reported) confirm the identified patterns of capital returns. This approach also reveals considerable heterogeneity within the sub-samples. The estimates show that marginal returns are (extremely) high - up to several hundred percent - at (very) low levels of capital, but decline very rapidly.

${ }^{16}$ We also distinguish between different types of capital goods (machines, transport means, or furniture) with no major implication with regard to our results. Similarly, including inventories into capital stocks does not affect the results.

${ }^{17}$ Note that female entrepreneurs account for 62 percent of low capital, 40 percent of medium capital, and only 26 percent of high capital entrepreneurs.
} 
As explained above, our results may be biased because of other omitted variables. The biases, in particular, ability bias, cannot be easily removed. A first straightforward attempt to solve this problem is to include ability proxies into the estimated equation. We have constructed two such proxies from the information available in the 1-2-3 surveys using principal component techniques. The first is an 'intellectual ability index', which includes information on literacy, language spoken at home, type of school (private or public), and father's schooling. The second index tries to capture 'financial literacy' and is constructed using questions regarding the knowledge of credit and other financial products. A third index measures whether the household has a tradition of being engaged in a particular business. Including these proxies into our regression (not reported) does again not affect the results.

\subsection{Returns to capital with a household fixed-effect}

An alternative to the inclusion of admittedly imperfect proxies to control for ability is to include a household fixed-effect into the above regressions. Quite a number of households own more than one enterprise, allowing to explore the co-variation of profits and capital across firms within the same household, thus removing the omitted household-level variables from the estimated equation. This procedure may mitigate the ability bias if entrepreneurs in the same household are more similar to each other in terms of their ability than they are compared to entrepreneurs outside the household, which is quite plausible.

An analysis of intra-household differences also allows us to test the assumption that factor returns are equated across different activities within the household. A rational household should equate returns, as otherwise Pareto-improving factor re-allocations would be possible. In other words, given fixed characteristics of the household certain constraints, for example credit or labour market constraints, faced by the individual entrepreneur should not be visible - within the household..$^{18}$ If instead, we detect differences in marginal returns to capital, we can take this as suggestive evidence for inefficient capital allocations. Theoretically, such inefficiencies could arise, for example, due to non-cooperative behaviour within the household. Optimal capital allocations, however, can also be consistent with differing marginal returns across activities in the presence of (a) some non-linearity in capital stocks that prevents the household from equalizing returns, or (b) risk and risk aversion. The above fairly smooth distributions of entry costs seem to suggest that non-linearities are unlikely to be of great importance in most of MSE activities, at least at lower levels of capital stock. Yet, if activities are associated with different risks and households choose to hold portfolios with different risks, they should equate risk-adjusted returns. In this case, the fixed-effects estimates should reflect the differences in returns that can be attributed to risk differences. Finally, while risk may be the main reason for $(\mathrm{d} \pi / d K)$ to be different from zero within-households, it cannot be ruled out that single activities, in some cases operated by different individuals, are faced with different constraints, for example different access to capital. In sum, the below fixed-effects results should not only be seen as a robustness check and an attempt to address ability bias, but also as a first attempt to reveal the possible causes of the observed pattern of returns to capital.

\footnotetext{
${ }^{18}$ In this case, the no-log specification should render zero coefficients for capital, while the log-specification should allow us to test the equation of marginal returns using capital profitabilities.
} 
Before we discuss the results, it should be noted that the fixed-effect estimation is prone to selection bias because of the implied reduction of the sample to only those MSEs in households with more than one enterprise. The results of the fixed effects estimates are reported in Table 9. To start with, we have 946 households owning 2079 enterprises (i.e. with at least two MSEs). Again, we exclude MSEs that report zero profits and/or zero capital and remove influential outliers from the respective (sub-) samples. In the case of the whole (sub) sample, this leads to a considerable reduction of the sample. The first set of estimates is based on only 600 households with 1301 firms. In addition to the double-log specification from above, we now also estimate a model without taking logs. The coefficients in the 'no log' specification can directly be interpreted as the marginal return to capital. ${ }^{19}$

\section{Place Table 9 here.}

Overall, the fixed-effects estimates yield similar results to the estimates without fixedeffects. ${ }^{20}$ Capital returns are of similar magnitude at low levels of capital. In the no-log specification, marginal returns are about 90 percent. As non-linearities in capital stocks are unlikely to explain these intra-household differences at low levels of capital stock, the identified returns may reflect the high risks associated to activities in this capital range. For the medium range, capital is not significant in either specification, but the magnitude is close to the above estimates. With monthly marginal returns of about 9 percent (last column of Table 9) the marginal returns at higher levels of capital are slightly higher than those obtained without fixed effects. At higher levels of capital, intra-household differences may be due to activity-specific capital constraints, but non-linearities, for example for machinery investment, are also likely to come into play. That returns are slightly higher in the fixedeffect model may, on the one hand, reflect the selection of more talented and entrepreneurial households into the sub-sample of those with at least two MSEs. It seems plausible that this selection effect is stronger at higher levels of capital. On the other hand, higher returns may also stem from the ability of diversified households to take (some more) risks and earn higher returns. ${ }^{21}$

The fixed-effects estimates hence support our finding of very high returns at low levels of capital. Of course, the reductions in sample size are considerable and one has to be careful not to draw too far-fetching conclusions from these estimates. Nonetheless, we do think

\footnotetext{
${ }^{19}$ Note that the sub-samples by capital size include only households, in which all enterprises have a capital stock that meets the sub-samples' conditions, for example capital stock smaller than 150 Int. \$.

${ }^{20}$ This also holds when we estimate the earlier specification without fixed effects on the much smaller samples. In the interpretation of the fixed effects estimates it should be taken into account that the two key variables under consideration, profits and capital stock, are likely to be measured with error. This problem is reinforced when only within-household variation is being used. Such measurement error would bias the returns to capital against zero; an effect that would be opposite to the ability bias.

${ }^{21}$ While capital stocks and profits between different MSEs within the same household (co-) vary enough to allow for estimating the fixed-effects model, other characteristics, like education and experience (and to some extent experience) vary little within the household. In addition, some MSEs are also operated by the same individual.
} 
that these results may also be taken as an indication that risk plays a major role in explaining the high returns at low levels of capital.

\subsection{Some more thoughts on the causes}

A thorough investigation of the causes of the observed pattern of capital returns goes beyond the scope of this paper and is left to future work. This section hence briefly presents only some suggestive evidence on the channels that might explain these patterns. More specifically, we assess the risks associated with activities at different levels of capital. Risks should be higher at low levels of capital if it really explains the observed high returns, as suggested by the fixed-effects estimates. We then make an attempt to proxy capital constraints and again look at these proxies at different levels of capital. We would expect MSEs with low levels of capital to be more constrained than those with more capital.

Although it is generally difficult to proxy risks - and more so in a cross-sectional dataset our survey offers a number of possibilities to construct risk proxies. First, we construct 'classical' proxies for risk, the variation of profits or sales. We chose to measure this variation at the country-sector level, where industries are disaggregated as finely as possible while keeping the number of observations in each country-sector cell at least at 30. Such a procedure yields 123 country-sector cells, for which we compute the coefficients of variation in profits and sales. Second, we use business risk perceptions of the entrepreneur. Specifically, we set a 'risk-of-closure dummy' to 1 if an entrepreneur sees the lack of clients or too much competition as a major business risk - which about 60 percent of all MSEs do. ${ }^{22}$ The sample means of these - admittedly imperfect - risk proxies are reported in Table 10 for different levels of capital stock.

Place Table 10 here.

The descriptive statistics in Table 10 support the view that risk may partly explain the observed pattern of returns. Both the coefficient of variation in profit and sales are lowest for higher levels of capital. The coefficient of variation of profits, likely the better indicator for risk, is higher for low levels of capital compared to the other two groups. High capital MSEs (with lower returns) are hence more frequently found in sectors with lower variation in profits. However, the differences in these indicators are far from being significant (the standard errors of the above means of the coefficients of variation are in a range of 0.5 to 0.9). According to the third indicator, risk is not highest for activities at low levels of capital. Rather, the threats to business survival appear to be strongest at medium levels of capital, a finding that does not fit with the idea of marginal returns reflecting high risks.

More detailed analysis of the above risk indicators, for example by country or by capital profitability (not reported), does not render consistent results. This is also why we think that the presented evidence provides at best some weak support for risk as major factor behind the above pattern of capital returns. Yet, in our view, these non-findings can be attributed to

\footnotetext{
${ }^{22}$ The corresponding question in the survey reads 'which are major threats to the existence of the MSE'.
} 
some extent to the lack of adequate risk (and risk aversion) proxies as well as the rather simple empirical approach. Furthermore, the effects of risk on returns (and capital stocks) may interact with capital market constraints, an interaction, which is ignored in our analysis.

Finally, we briefly examine the possible role of capital constraints in explaining the observed pattern. To this end, Table 11 reports three proxies of capital constraints, again by capital stock range. At least for low levels of capital, for which we find extremely high marginal returns, we would expect MSEs to be severely capital constrained.

Place Table 11 here.

Table 11 shows that MSEs with low levels of capital stock are indeed more capital constrained than others. 88 percent of these firms have financed their capital stock only out of own savings without recurring to any source of external funds, including formal and informal credit, family funds or support from friends. ${ }^{23}$ This 'only' holds for 81 and 77 percent at medium and high levels of capital stock, respectively. Similarly, 14 percent of the entrepreneurs report to be liquidity constrained, ${ }^{24}$ compared to 10 percent in the other two groups. When we split up MSEs by the wealth of the households, in which they are operated, the empirical picture is also in line with expectations. 32 percent of the high capital MSEs can be found in households in the highest wealth quintile. Yet, there are both rich households with low capital MSEs and poor households with high capital MSEs.

While these findings are all in line with expectations, they hardly provide sufficient evidence of the importance of capital constraints. In fact, the descriptive statistics are somewhat fuzzy. The relatively high share of low-capital MSEs in high wealth households for example, may rather be taken as an indication that there should be further factors explaining capital accumulation. For instance, as seen above, many households seem to practice extensive growth, i.e. they invest in several small or very small firms instead of setting up one large firm. Hence, in this case it would mean, this households are not capital constrained, but rather risk averse. Moreover and more generally, as also McKenzie and Woodruff (2006) pointed out, MSEs should, in principle, be able to re-invest their very high returns to accumulate capital. Capital constraints would then only partly be reflected in high returns.

\section{Conclusions}

We have analysed the patterns of capital entry barriers into informal activities as well as returns to invested capital using a unique micro data set on informality covering seven urban centres in West-Africa. Our assessment of initial investment of MSEs suggests that most informal activities exhibit important entry barriers, at least when operating costs are taken into account. We can also identify an informal sub-sector, for which fixed costs of entry are

\footnotetext{
${ }^{23}$ For each item of capital stock, the entrepreneur is asked for the source of funding. From this information, we construct the dummy for 'No access to external capital'.

${ }^{24}$ The 'liquidity constraints' dummy is set to 1 if entrepreneurs perceive the lack of liquidity as a major threat to survival of their enterprise.
} 
negligible. A relatively small fraction of informal entrepreneurs undertakes very substantial initial capital investments, in particular in the transport sector. These findings in conjunction with our descriptive analysis of MSE characteristics point at quite some heterogeneity among informal activities.

We also find heterogeneous returns to capital. Marginal returns are extremely high at low levels of capital stock. In this capital range, we consistently find marginal monthly returns of at least 70 percent. However, we also show that marginal returns decline very rapidly with increasing levels of invested capital. At capital stocks above 150 Int. \$, we find monthly marginal returns of four to seven percent using a simple OLS approach and around nine percent using a household fixed-effects estimator. The annualised return at higher levels of capital would thus be around 50 to 70 percent, which is much higher what typical microcredit providers effectively charge in interest (between 15 and 25 percent) and within the range of informal money lenders' rates (60 percent and more).

Our findings on returns are in line with earlier studies on small-scale activities from different contexts. We hence provide yet another piece of evidence that the informal sector does not primarily host small-scale activities with low capital stocks and close to zero returns, as suggested by our simple theoretical exposition and often articulated in the discourse on the informal sector. Rather, MSEs with very low capital stocks - or at least an important share of them - earn high returns and hence seem to have the potential to grow out of poverty. While our static analysis remains silent on this important dynamic dimension, we provide some evidence on the reasons that hold back these entrepreneurs.

We analyse in particular capital constraints and risk as possible causes of high returns at low levels of capital. While MSEs with low levels of capital stock are likely to be severely capital constrained, their access to capital is not different enough from other MSEs to explain the extreme differences in returns across the capital stock distribution. Our approach to assess the role of risk is somewhat innovative, as we interpret our finding of high marginal returns at low levels of capital stock in a household fixed-effects profit function estimation to mainly result from differences in risks between the informal activities operated by the household. We hence think to be able to provide some evidence in favour of a prominent role for risk in explaining high returns to capital in small-scale economic activities. Yet, this piece of evidence should be taken with care, as our results cannot be fully corroborated by other indicators of risks we consider. Finally, we understand this work as a first step towards a better understanding of the constraints and opportunities faced by informal entrepreneurs in Sub-Saharan Africa. A more detailed investigation into the causes of the heterogeneity in returns is needed in particular since informal activities are likely to remain the main income source of the poor in that region in the decades to come. 


\section{Bibliography}

Aghion, P. and P. Bolton, "A theory of trickle-down growth and development," Review of Economic Studies, 64, 151-172, 1997.

Banerjee, A. and E. Duflo, "Do Firms Want to Borrow More? Testing Credit Constraints Using a Directed Lending Program," CEPR Discussion Papers 4681, 2004.

Banerjee, A. and E. Duflo, "Growth Theory through the Lens of Development Economics," in: Aghion, P. and S. Durlauf, ed., Handbook of Economic Growth, 473-552, Elsevier, 2005.

Banerjee, A. and A. Newman, "Occupational choice and the process of Development," Journal of Political Economy, 101, 274-298, 1993.

Belsley, D. A., Kuh, E. and R.E. Welsch, Regression Diagnostics, Wiley, New York, 1980.

Bigsten, A., Collier, P., Dercon, S., Fafchamps, M., Gauthier, B., Gunning, J., Oduro, A., Oostendorp, R., Patillo, C., Soderbom, M., Teal, F., and A. Zeufack, "Credit Constraints in Manufacturing Enterprises in Africa," Journal of African Economies, 12, 104-125, 2003.

Brilleau A., Roubaud, F., and C. Torelli, "L'emploi, le chômage et les conditions d'activité, Enquêtes 1-2-3, phase ," Stateco, 99, 54-84, 2005.

Brilleau A., Ouedraogo, E., and F. Roubaud, "L'Enquête 1-2-3 dans les Principales Agglomérations de I'UEMOA: la Consolidation d'une Méthode," Stateco, 99, 15-19, 2005.

Cunningham, W., and W.F. Maloney, "Heterogeneity in the Mexican Micro-enterprise Sector: An Application of Factor and Cluster Analysis," Economic Development and Cultural Change, 5, 131-156, 2001.

De Mel, S., McKenzie, D., and C. Woodruff, "Returns to Capital in Microenterprises: Evidence from a Field Experiment, " The Quarterly Journal of Economics, 123, 1329-1372, 2008.

Fields, G. "Labour Market Modelling and the Urban Informal Sector: Theory and Evidence," in: Turnham, D., Salomé, B., and A. Schwartz, ed., The Informal Sector Revisited, OECD Development Centre Seminar Series, OECD, Paris, 49-69, 1990.

Galor, O. and J. Zeira, "Income Distribution and Macroeconomics," Review of Economic Studies, 60, 35-52, 1993.

Hart, K., "Informal Income Opportunities and Urban Employment in Ghana," The Journal of Modern African Studies, 11, 61-89, 1973.

Henley, A., Arabsheibani, R., and F. Carneiro, "On Defining and Measurement the Informal Sector," World Bank Policy Research Working Paper 3866, World Bank, Washington D.C., 2006.

Kremer, M., Lee, J.N., and J.M. Robinson, J.M, "The Return to Capital for Small Retailers in Kenya: Evidence from Inventories," Mimeo, Harvard University, 2010.

Lloyd-Ellis, H. and D. Bernhardt, "Enterprise, Inequality and Economic Development," Review of Economic Studies, 67, 147-168, 2000. 
Malony, W., "Informality Revisited," World Development, 32, 1159-1176, 2004.

McKenzie, D.J. and C. Woodruff, "Do Entry Costs Provide an Empirical Basis for Poverty Traps? Evidence from Mexican Microenterprises," Economic Development and Cultural Change, 55, 3-42, 2006.

Moser, C., "Informal Sector or Petty Commodity Production: Dualism or Dependence in Urban Development?," World Development, 6, 1041-1064, 1978.

Peatti, L., "An Idea in Good Currency and How It Grew: The Informal Sector," World Development. 15, 851-860, 1987.

Rakowsky, C., "Convergence and Divergence in the Informal Sector Debate: A Focus on Latin America 1984-92," World Development, 22, 501-516, 1994.

Roubaud F., "Mixed Surveys Using the Modular Approach," in: ILO Manual on Surveys of Informal Employment and Informal Sector, ILO, Geneva, 2008.

Schündeln, M. "Returns to Capital and Financial Constraints," Mimeo, Harvard University, 2004.

Schündeln, M., "Modeling Firm Dynamics to Identify the Cost of Financing Constraints in Ghanaian Manufacturing," Mimeo, Harvard University, 2006.

Tybout, J., "Credit Rationing and Investment Behavior in a Developing Country," Review of Economics and Statistics, 65, 598-607, 1983.

Udry, C. and S. Anagol, "The Return to Capital in Ghana," American Economic Review, 96, 388-393, 2006. 
Figure 1: Borrowing constraints and marginal returns to capital

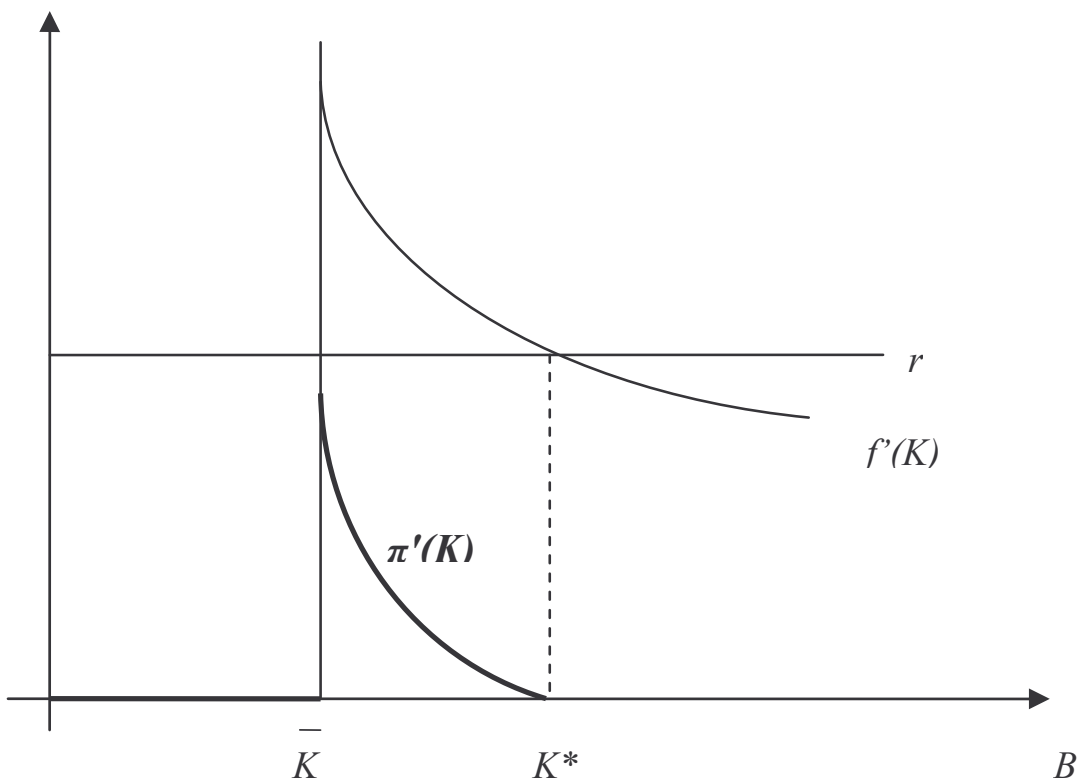

Source: Authors' compilation.

Figure 2: Histograms of initial investment (values in current Int. \$)
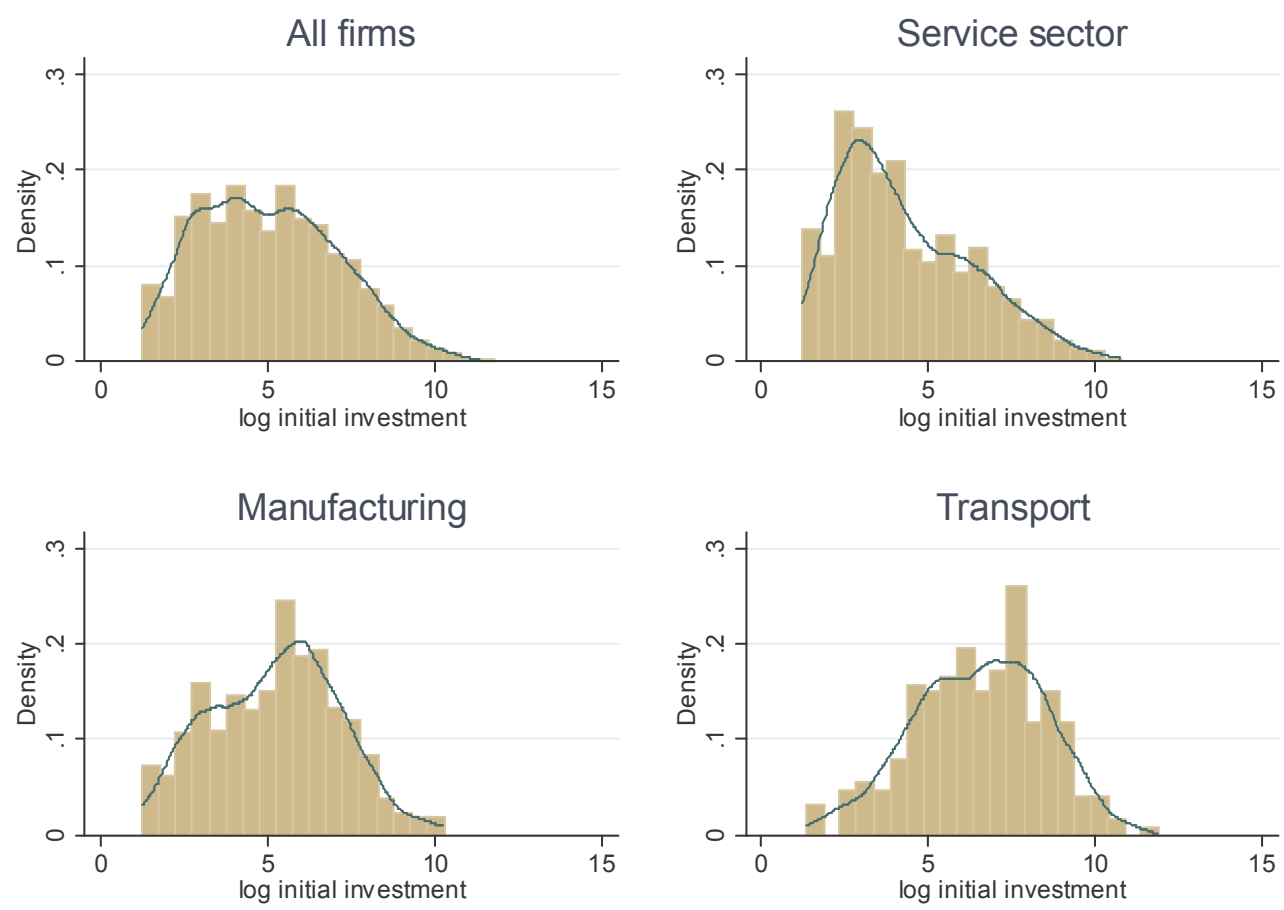

Source: Authors' computation based on 1-2-3 surveys (Phase 2, 2001/02, AFRISTAT, DIAL, INS). Note: The histograms exclude zero investment. 
Table 1: Employment by sector in seven West-African urban centres (in percent)

\begin{tabular}{lrrrrrrrr}
\hline Principal employment & Cotonou & Ouaga. & Abidjan & Bamako & Niamey & Dakar & Lomé & Total \\
\hline Public administration & 6.3 & 10.4 & 5.5 & 7.5 & 13.5 & 5.7 & 5.2 & 6.6 \\
Public firm & 2.2 & 2.3 & 1.1 & 2.5 & 1.8 & 1.8 & 2.3 & 1.8 \\
Private formal firm & 9.9 & 11.8 & 17.6 & 11.4 & 11.8 & 15.0 & 10.5 & 14.2 \\
Private informal firm & 80.3 & 73.4 & 74.7 & 77.5 & 71.1 & 76.4 & 81.0 & 76.2 \\
of which & & & & & & & & \\
$\quad$ Owners & 63.7 & 67.5 & 60.4 & 73.4 & 72.2 & 65.2 & 68.6 & 65.0 \\
Family workers & 19.2 & 16.3 & 16.1 & 8.6 & 14.5 & 17.6 & 13.6 & 15.5 \\
$\quad$ Non-family workers & 17.1 & 16.2 & 23.5 & 18.0 & 13.3 & 17.2 & 17.8 & 19.5 \\
$\quad$ Associations & 1.3 & 2.1 & 1.1 & 1.1 & 1.8 & 1.1 & 1.0 & 1.2 \\
\hline
\end{tabular}

Source: Brilleau, Roubaud and Torelli (2005), and authors' computations based on 1-2-3 surveys (Phase 2, 2001/02, AFRISTAT, DIAL, INS).

Table 2: Basic descriptive statistics of informal MSEs, by quintiles of capital stock (values in 2001 international Dollar)

\begin{tabular}{|c|c|c|c|c|c|c|c|}
\hline & Mean & Median & $1(0-10)$ & $2(10-42)$ & $\begin{array}{c}3(42- \\
155) \\
\end{array}$ & $\begin{array}{c}4(155- \\
731) \\
\end{array}$ & $\begin{array}{l}5(733- \\
106166)\end{array}$ \\
\hline Age of the enterprise & 7.4 & 5 & 6.7 & 7.1 & 8.2 & 7.7 & 7.4 \\
\hline Owner's age & 36.3 & 35 & 35.2 & 35.8 & 36.8 & 36.1 & 37.8 \\
\hline Owner's years of schooling & 3.7 & 3 & 3.3 & 2.5 & 3.2 & 3.9 & 5.5 \\
\hline Owner's experience & 6.9 & 4 & 6.1 & 6.6 & 7.6 & 7.1 & 6.9 \\
\hline Owner female & 0.51 & & 0.6 & 0.7 & 0.5 & 0.4 & 0.3 \\
\hline Firm size & 1.6 & 1 & 1.1 & 1.2 & 1.5 & 1.9 & 2.5 \\
\hline $\begin{array}{l}\text { Share of pure self- } \\
\text { employment } \\
\text { Monthly profit (in } 2001\end{array}$ & 0.69 & & 0.9 & 0.9 & 0.7 & 0.6 & 0.4 \\
\hline $\begin{array}{l}\text { international Dollar) } \\
\text { Capital stock (in } 2001\end{array}$ & 380.3 & 112 & 206.7 & 179.9 & 323 & 412 & 783.3 \\
\hline international Dollar) & 997.2 & 76.8 & 2.1 & 23.4 & 83.6 & 351.8 & 4554.4 \\
\hline Number of observations & 6521 & 6521 & 1324 & 1293 & 1306 & 1302 & 1296 \\
\hline
\end{tabular}

Notes: Quintiles of capital (min and max capital in Int. \$ in parentheses).

Source: Authors' computation based on 1-2-3 surveys (Phase 2, 2001/02, AFRISTAT, DIAL, INS).

Notes: 2001 international dollars are on the basis of the Purchasing Power Parity converters for GDP from the World Development Indicators (World Bank, 2010). 
Table 3: Industry composition of informal MSEs by country (number of observations and shares in percent)

\begin{tabular}{|c|c|c|c|c|c|c|c|c|}
\hline Industry/City & Cotonou & Ouaga. & Abidjan & Bamako & Niamey & Dakar & Lomé & Total \\
\hline \multirow{2}{*}{$\begin{array}{l}\text { Clothing and } \\
\text { apparel }\end{array}$} & 98 & 78 & 122 & 137 & 56 & 98 & 117 & 706 \\
\hline & 10.5 & 8.2 & 12.3 & 14.0 & 7.9 & 9.8 & 12.3 & 10.8 \\
\hline $\begin{array}{l}\text { Other } \\
\text { manufacturing }\end{array}$ & 102 & 223 & 103 & 134 & 225 & 151 & 106 & 1,044 \\
\hline \& food & 11.0 & 23.3 & 10.4 & 13.7 & 31.6 & 15.2 & 11.1 & 16.0 \\
\hline \multirow{2}{*}{ Construction } & 70 & 68 & 68 & 101 & 39 & 91 & 55 & 492 \\
\hline & 7.5 & 7.1 & 6.9 & 10.3 & 5.5 & 9.1 & 5.8 & 7.5 \\
\hline \multirow{2}{*}{$\begin{array}{l}\text { Wholesale/retail } \\
\text { shops }\end{array}$} & 104 & 103 & 102 & 92 & 46 & 109 & 100 & 656 \\
\hline & 11.2 & 10.8 & 10.3 & 9.4 & 6.5 & 10.9 & 10.5 & 10.1 \\
\hline \multirow{2}{*}{ Petty trading } & 235 & 251 & 262 & 265 & 194 & 283 & 279 & 1,769 \\
\hline & 25.3 & 26.2 & 26.5 & 27.1 & 27.2 & 28.4 & 29.2 & 27.1 \\
\hline \multirow{2}{*}{$\begin{array}{l}\text { Hotels and } \\
\text { restaurants }\end{array}$} & 89 & 78 & 80 & 40 & 8 & 50 & 66 & 411 \\
\hline & 9.6 & 8.2 & 8.1 & 4.1 & 1.1 & 5.0 & 6.9 & 6.3 \\
\hline \multirow{2}{*}{ Repair services } & 67 & 51 & 63 & 49 & 41 & 36 & 68 & 375 \\
\hline & 7.2 & 5.3 & 6.4 & 5.0 & 5.8 & 3.6 & 7.1 & 5.8 \\
\hline \multirow{2}{*}{ Transport } & 80 & 22 & 43 & 37 & 26 & 54 & 39 & 301 \\
\hline & 8.6 & 2.3 & 4.3 & 3.8 & 3.7 & 5.4 & 4.1 & 4.6 \\
\hline \multirow{2}{*}{ Other services } & 85 & 83 & 147 & 124 & 78 & 125 & 125 & 767 \\
\hline & 9.1 & 8.7 & 14.9 & 12.7 & 10.9 & 12.5 & 13.1 & 11.8 \\
\hline \multirow[t]{2}{*}{ Total } & 930 & 957 & 990 & 979 & 713 & 997 & 955 & 6,521 \\
\hline & 100 & 100 & 100 & 100 & 100 & 100 & 100 & 100 \\
\hline
\end{tabular}

Source: Authors' computation based on 1-2-3 survey (Phase 2, 2001/02, AFRISTAT, DIAL, INS).

Note: Shares (in percent) in italics.

Table 4: Perceived problems faced by MSEs in the clothing and apparel sector by enterprise age

\begin{tabular}{|c|c|c|c|c|c|}
\hline & All & & Enterpr & e age & \\
\hline Problem & & $\begin{array}{c}\text { less than } 1 \\
\text { year }\end{array}$ & $2-3$ years & $4-8$ years & more than 8 \\
\hline Access to raw materials & 0.25 & 0.35 & 0.22 & 0.25 & 0.23 \\
\hline Not enough clients & 0.67 & 0.68 & 0.72 & 0.67 & 0.64 \\
\hline Too much competition & 0.59 & 0.56 & 0.59 & 0.59 & 0.60 \\
\hline Access to credit & 0.48 & 0.46 & 0.46 & 0.47 & 0.51 \\
\hline Credit too expensive & 0.28 & 0.27 & 0.34 & 0.25 & 0.27 \\
\hline Recruitment of qualified personnel & 0.12 & 0.13 & 0.14 & 0.10 & 0.11 \\
\hline Lack of adequate locality & 0.38 & 0.43 & 0.38 & 0.40 & 0.34 \\
\hline Lack of machines, equipment & 0.44 & 0.46 & 0.46 & 0.45 & 0.40 \\
\hline Technical difficulties of production & 0.16 & 0.16 & 0.19 & 0.17 & 0.15 \\
\hline Management difficulties & 0.13 & 0.07 & 0.14 & 0.14 & 0.13 \\
\hline Too many regulations and taxes & 0.10 & 0.07 & 0.09 & 0.11 & 0.11 \\
\hline Number of observations & 706 & 93 & 164 & 194 & 255 \\
\hline
\end{tabular}

Source: Authors' computation based on 1-2-3 survey (Phase 2, 2001/02, AFRISTAT, DIAL, INS). 
Table 5: Entry barriers to informal enterprises (values in current Int. \$)

\begin{tabular}{|c|c|c|c|c|c|c|c|c|c|}
\hline & Obs. & $\begin{array}{l}\text { Share } 0 \\
\text { init. inv. }\end{array}$ & Mean & Mean $(>0)$ & $\mathrm{p} 10$ & $\mathrm{p} 25$ & p50 & p75 & p99 \\
\hline Clothing and apparel & 319 & 0.18 & 813 & 994 & 0 & 14 & 233 & 615 & 10955 \\
\hline Other manfg \& food & 493 & 0.23 & 708 & 919 & 0 & 5 & 46 & 364 & 20781 \\
\hline Construction & 128 & 0.30 & 262 & 377 & 0 & 0 & 31 & 119 & 3961 \\
\hline Wholesale/retail shops & 329 & 0.39 & 684 & 1119 & 0 & 0 & 24 & 193 & 14974 \\
\hline Petty traders & 943 & 0.38 & 177 & 288 & 0 & 0 & 10 & 35 & 2607 \\
\hline Hotels and restaurants & 229 & 0.14 & 802 & 937 & 0 & 30 & 93 & 396 & 8860 \\
\hline Repair services & 159 & 0.17 & 1150 & 1386 & 0 & 36 & 200 & 708 & 30347 \\
\hline Transport & 171 & 0.29 & 3645 & 5109 & 0 & 0 & 932 & 3397 & 34074 \\
\hline Other services & 373 & 0.42 & 760 & 1318 & 0 & 0 & 15 & 296 & 15401 \\
\hline Total & 3144 & 0.31 & 734 & 1060 & 0 & 0 & 30 & 275 & 12740 \\
\hline
\end{tabular}

Source: Authors' computation based on 1-2-3 survey (Phase 2, 2001/02, AFRISTAT, DIAL, INS).

Table 6: Initial investment and other start-up costs relative to income levels (values in current Int. \$)

\begin{tabular}{|c|c|c|c|c|c|c|c|c|c|c|c|}
\hline & \multicolumn{2}{|c|}{$\begin{array}{c}\text { Initial } \\
\text { investment }\end{array}$} & \multicolumn{2}{|c|}{$\begin{array}{l}\text { Non-labor } \\
\text { expenses }\end{array}$} & \multicolumn{2}{|c|}{ Raw material } & \multicolumn{2}{|c|}{ Inventory } & \multicolumn{2}{|c|}{$\begin{array}{l}\text { Labor } \\
\text { expenses }\end{array}$} & \multirow{2}{*}{$\begin{array}{c}\text { Monthly } \\
\text { profits } \\
\text { p50 }\end{array}$} \\
\hline & Mean & p50 & Mean & p50 & Mean & p50 & Mean & p50 & Mean & p50 & \\
\hline $\begin{array}{l}\text { Clothing and } \\
\text { apparel } \\
\text { Other manfg \& }\end{array}$ & 813 & 233 & 164 & 58 & 111 & 27 & 5 & 0 & 5 & 0 & 77 \\
\hline food & 708 & 46 & 396 & 170 & 308 & 105 & 27 & 0 & 8 & 0 & 98 \\
\hline Construction & 262 & 31 & 624 & 34 & 509 & 0 & 9 & 0 & 32 & 0 & 187 \\
\hline $\begin{array}{l}\text { Wholesale/retail } \\
\text { shops }\end{array}$ & 684 & 24 & 1477 & 414 & 48 & 0 & 1318 & 359 & 4 & 0 & 131 \\
\hline Petty traders & 177 & 10 & 511 & 182 & 52 & 0 & 424 & 136 & 3 & 0 & 70 \\
\hline $\begin{array}{l}\text { Hotels and } \\
\text { restaurants }\end{array}$ & 802 & 93 & 944 & 545 & 590 & 384 & 263 & 0 & 9 & 0 & 170 \\
\hline Repair services & 1150 & 200 & 306 & 88 & 87 & 0 & 95 & 0 & 11 & 0 & 125 \\
\hline Transport & 3645 & 932 & 683 & 284 & 92 & 0 & 31 & 0 & 17 & 0 & 293 \\
\hline Other services & 760 & 15 & 230 & 35 & 28 & 0 & 66 & 0 & 8 & 0 & 102 \\
\hline Total & 734 & 30 & 560 & 151 & 157 & 0 & 304 & 0 & 8 & 0 & 105 \\
\hline
\end{tabular}

Source: Authors' computation based on 1-2-3 surveys (Phase 2, 2001/02, AFRISTAT, DIAL, INS).

Note: Non-labour expenses include raw materials, inventories, and all other recurrent expenses (for example fuel). 
Table 7: Returns to capital - results from OLS including capital-country interactions

\begin{tabular}{|c|c|c|c|c|c|}
\hline & & All & $\begin{array}{c}\text { Capital }<150 \text { Int. } \\
\$\end{array}$ & $\begin{array}{c}\text { Capital >150 Int. \$ } \\
\&<1000 \text { Int. \$ }\end{array}$ & $\begin{array}{c}\text { Capital > } 1000 \\
\text { Int. \$ }\end{array}$ \\
\hline \multirow{2}{*}{\multicolumn{2}{|c|}{ Log capital }} & $0.180 * * *$ & $0.290 * * *$ & $0.343 * *$ & $0.493 * * *$ \\
\hline & & $(0.021)$ & (0.049) & $(0.167)$ & (0.117) \\
\hline \multirow{12}{*}{$\begin{array}{l}\text { Log capital x } \\
\text { dummy for }\end{array}$} & \multirow{2}{*}{ Cotonou } & 0.049 & -0.005 & -0.105 & $-0.235^{*}$ \\
\hline & & $(0.034)$ & (0.099) & $(0.218)$ & $(0.141)$ \\
\hline & \multirow{2}{*}{ Ouaga } & $0.062 * *$ & -0.006 & -0.201 & 0.207 \\
\hline & & $(0.029)$ & $(0.074)$ & $(0.233)$ & $(0.161)$ \\
\hline & \multirow{2}{*}{ Abijan } & -0.002 & -0.091 & $-0.450 * *$ & -0.104 \\
\hline & & $(0.034)$ & (0.079) & $(0.215)$ & $(0.163)$ \\
\hline & \multirow{2}{*}{ Bamako } & $0.080 * *$ & 0.089 & $-0.422^{*}$ & -0.036 \\
\hline & & $(0.033)$ & $(0.075)$ & $(0.224)$ & $(0.216)$ \\
\hline & \multirow{2}{*}{ Niamey } & $0.071^{*}$ & $0.146^{*}$ & $-0.411^{*}$ & $-0.320 *$ \\
\hline & & $(0.037)$ & $(0.083)$ & $(0.246)$ & (0.180) \\
\hline & \multirow{2}{*}{ Lome } & 0.049 & -0.048 & 0.080 & 0.002 \\
\hline & & $(0.030)$ & $(0.071)$ & $(0.211)$ & $(0.154)$ \\
\hline \multicolumn{2}{|c|}{ Additional controls } & $\begin{array}{r}\text { Log labour and } \\
\text { owner's educ } \\
\text { female, industry }\end{array}$ & $\begin{array}{l}\text { Log labour-country i } \\
\text { ation-country interac } \\
\text { dummies, country du }\end{array}$ & $\begin{array}{l}\text { nteractions, Owner' } \\
\text { ctions, Owner's expe } \\
\text { ummies, country-ind }\end{array}$ & $\begin{array}{l}\text { education and } \\
\text { ence, owner } \\
\text { stry interactions }\end{array}$ \\
\hline \multirow{2}{*}{\multicolumn{2}{|c|}{$\begin{array}{l}\text { R-squared } \\
\mathrm{N}\end{array}$}} & 0.392 & 0.339 & 0.350 & 0.425 \\
\hline & & 5082 & 2742 & 1400 & 935 \\
\hline \multirow{7}{*}{$\begin{array}{l}\text { Implied MRK (at } \\
\text { average P and } \\
\text { K) }\end{array}$} & Dakar & 0.10 & 0.71 & 0.34 & 0.10 \\
\hline & Cotonou & 0.03 & 0.70 & 0.14 & 0.03 \\
\hline & Ouaga & 0.07 & 0.89 & 0.14 & 0.13 \\
\hline & Abijan & 0.10 & 1.07 & -0.13 & 0.07 \\
\hline & Bamako & 0.13 & 2.39 & -0.08 & 0.09 \\
\hline & Niamey & 0.06 & 1.51 & -0.04 & 0.01 \\
\hline & Lome & 0.03 & 0.39 & 0.13 & 0.03 \\
\hline
\end{tabular}

Source: Authors' computation based on 1-2-3 surveys (Phase 2, 2001/02, AFRISTAT, DIAL, INS).

Notes: $* \mathrm{p}<0.05, * * \mathrm{p}<0.01, * * * \mathrm{p}<0.001$. Robust standard errors corrected for clustering at the 'segment'-level (around 10 observations) in parentheses. MRK = marginal monthly return to capital. The full results are available from the authors on request. 
Table 8: Returns to capital - results from OLS including capital-industry interactions

\begin{tabular}{|c|c|c|c|c|c|}
\hline & & All & $\begin{array}{c}\text { Capital }<150 \text { Int. } \\
\$\end{array}$ & $\begin{array}{l}\text { Capital >150 Int. } \\
\$ \&<1000 \text { Int. \$ }\end{array}$ & $\begin{array}{c}\text { Capital > } 1000 \\
\text { Int. \$ }\end{array}$ \\
\hline \multirow{2}{*}{ Log capital } & & $0.205^{* * *}$ & $0.363 * * *$ & $0.288 * * *$ & $0.510 * * *$ \\
\hline & & $(0.018)$ & $(0.041)$ & $(0.038)$ & (0.088) \\
\hline \multirow{6}{*}{$\begin{array}{l}\text { Log capital x } \\
\text { dummy for }\end{array}$} & Construction, & $0.096 * * *$ & $0.155^{*}$ & 0.003 & -0.136 \\
\hline & hotels, transport & $(0.026)$ & $(0.073)$ & $(0.050)$ & (0.110) \\
\hline & Trade & 0.007 & -0.084 & -0.034 & -0.043 \\
\hline & Irade & $(0.024)$ & $(0.054)$ & (0.059) & (0.139) \\
\hline & Repair and other & -0.038 & $-0.235 * * *$ & -0.034 & -0.087 \\
\hline & services & $(0.025)$ & (0.059) & $(0.056)$ & $(0.130)$ \\
\hline \multicolumn{2}{|c|}{ Additional controls } & \multicolumn{4}{|c|}{$\begin{array}{c}\text { Log labour and Log labour-country interactions, Owner's education and } \\
\text { owner's education-country interactions, Owner's experience, owner } \\
\text { female, industry dummies, country dummies, country-industry } \\
\text { interactions }\end{array}$} \\
\hline \multirow{2}{*}{$\begin{array}{l}\text { R-squared } \\
\mathrm{N}\end{array}$} & & 0.3807 & 0.3339 & 0.3641 & 0.3961 \\
\hline & & 5091 & 2748 & 2338 & 932 \\
\hline \multirow{4}{*}{$\begin{array}{l}\text { Implied MRK (at } \\
\text { mean P and K) }\end{array}$} & Manufacturing & 0.06 & 1.31 & 0.06 & 0.06 \\
\hline & $\begin{array}{l}\text { Construction, } \\
\text { hotels, transport }\end{array}$ & 0.09 & 2.68 & 0.07 & 0.06 \\
\hline & Trade & 0.10 & 1.35 & 0.06 & 0.07 \\
\hline & $\begin{array}{l}\text { Repair and other } \\
\text { services }\end{array}$ & 0.04 & 0.47 & 0.04 & 0.04 \\
\hline
\end{tabular}

Source: Authors' computation based on 1-2-3 surveys (Phase 2, 2001/02, AFRISTAT, DIAL, INS).

Notes: ${ }^{*} p<0.05, * * p<0.01, * * * p<0.001$. Robust standard errors corrected for clustering at the 'segment'-level (around 10 observations) in parentheses. MRK = marginal monthly return to capital. The full results are available from the authors on request. 


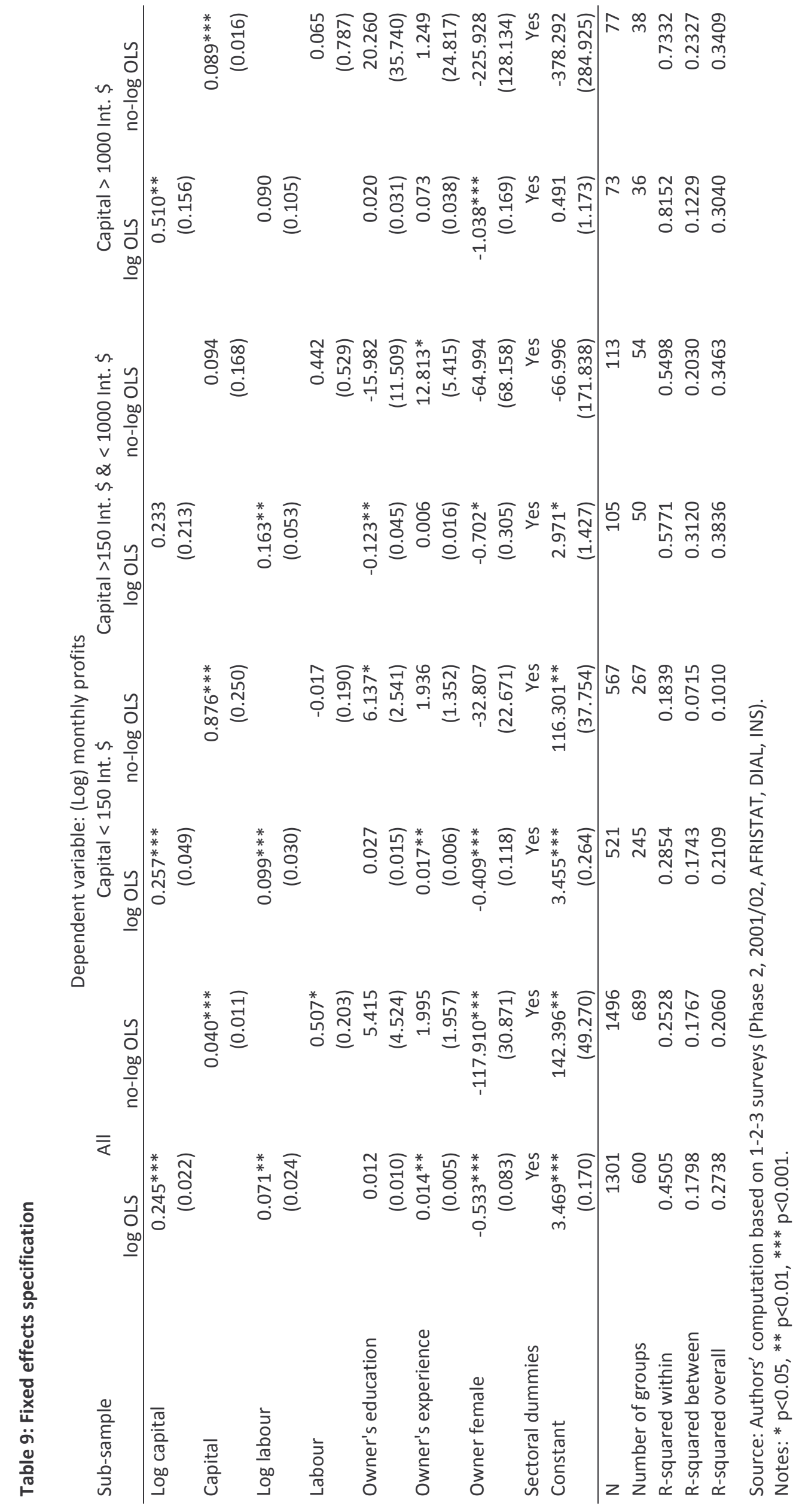


Table 10: Risk proxies at different levels of capital stock

\begin{tabular}{lccc}
\hline & $\begin{array}{c}\text { Capital }<150 \text { Int. } \\
\$\end{array}$ & $\begin{array}{c}\text { Capital }>150 \text { Int. } \\
\$ \&<1000 \text { Int. } \$\end{array}$ & $\begin{array}{c}\text { Capital }>1000 \\
\text { Int. \$ }\end{array}$ \\
\hline $\begin{array}{l}\text { Coefficient of variation in } \\
\text { sales } \\
\begin{array}{l}\text { Coefficient of variation in } \\
\text { profits }\end{array}\end{array}$ & 1.98 & 2.01 & 1.97 \\
$\begin{array}{l}\text { Perceived risk of closure } \\
\text { due to lack of clients or } \\
\text { too much competition }\end{array}$ & 2.04 & 1.93 & 1.91 \\
\hline
\end{tabular}

Source: Authors' computation based on 1-2-3 surveys (Phase 2, 2001/02, AFRISTAT, DIAL, INS).

Table 21: Capital constraint proxies at different levels of capital stock

\begin{tabular}{lccc}
\hline & $\begin{array}{c}\text { Capital }<150 \text { Int. } \\
\$\end{array}$ & $\begin{array}{c}\text { Capital }>150 \text { Int. } \\
\$ \&<1000 \text { Int. } \$\end{array}$ & $\begin{array}{c}\text { Capital }>1000 \\
\text { Int. \$ }\end{array}$ \\
\hline No access to external & 0.88 & 0.81 & 0.77 \\
capital & 0.14 & 0.10 & 0.10 \\
$\begin{array}{l}\text { Liquidity constraints } \\
\text { Access to formal credit }\end{array}$ & 0.03 & 0.03 & 0.07 \\
$\begin{array}{l}\text { Share in lowest wealth } \\
\text { quintile }\end{array}$ & 0.26 & 0.16 & 0.09 \\
$\begin{array}{l}\text { Share in highest wealth } \\
\text { quintile }\end{array}$ & 0.15 & 0.22 & 0.32 \\
\hline
\end{tabular}

Source: Authors' computation based on 1-2-3 surveys (Phase 2, 2001/02, AFRISTAT, DIAL, INS). 